\section{Entrepreneurial experiences}

Setting out to create and build a company can present many challenges. This month, entrepreneurs describe their experiences and highlight some of the lessons they've learned.

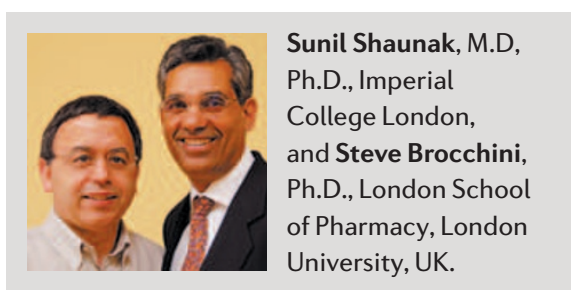

In 2002, Sunil Shaunak and Steve Brocchini founded PolyTherics, which focuses on biomedical polymers for therapeutic uses. Five years later, after obtaining seed funding from the UK government and the Wellcome Trust, they have established international partnerships for the development of two new drugs based on their platform technologies, one for hepatitis $\mathrm{C}$ and the other for leishmaniasis. The key feature of these agents - the first of which is a modified version of interferon- $\alpha 2$, an established therapy for hepatitis C - is that they could be provided at a price low enough to allow them to be made much more widely available in developing countries than existing versions.

Brocchini and Shaunak had been discussing research ideas for a couple of years when they decided to pool their expertise and create a company to realise the potential of several of the patents they had obtained through their research. Bringing together a clinical scientist (Shaunak) and a non-clinical scientist (Brocchini) from two different institutions "made a lot of sense because each person and their institution brought complementary skills to the table - this diversity being a much better formula for success given the complexity of the research," recalls Brocchini. They also recognised and valued the importance of trust, a genuine debate and discipline for delivering the ambitious goals that they have set. In addition, a close working relationship has enabled them to educate each other about their respective disciplines and to bridge large interdisciplinary divides - a factor they consider to be the key to their success.

This teamwork has helped them progress while dealing with the harsh realities of fund raising. "There is the fundamental problem of risk aversion and the need for a quick return on an investment," says Brocchini. "You'll be given $\mathrm{f} 200,000$ for 18 months when you really need $f 2$ million for 5 years! Everyone is keen to invest after you have completed the Phase II clinical trial because the idea is a no-brainer at that stage". Shaunak adds: "This problem arises

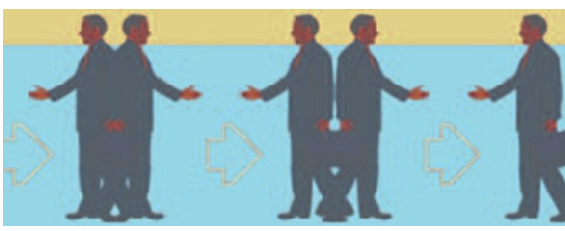

because the funding gap lies at the interface of the new chemical entity on our laboratory bench and the drug's first administration to a patient".

As they move forwards, a major driving force is the need to ensure that the final cost of any new drug is within the reach of the patients who need it, wherever they live in the world. To achieve this goal, they are now working in partnership with scientists in other countries such as India. "The cost of developing new drugs in the UK has become very high, so we have actively pursued global co-development partnerships that use our technologies to develop much-needed medicines. This also serves to validate and evolve our technologies," says Brocchini. "A lot of people around the world are keen to work with us because of the urgent global need for costaffordable medicines," adds Shaunak. Together, they have come to recognise their global social responsibility for ensuring that the healthcare problems of patients in developing countries are addressed. As Brocchini sums up: “It's more than setting an example, you can't be outside the social equation any more - you have to participate. For us, affordability is an unmet global medical need."

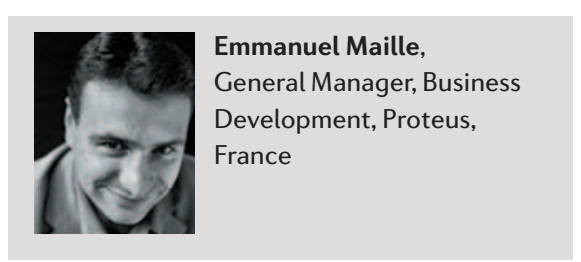

Many start-up companies in the life sciences are initially based on research that the founders have carried out in academia. For Emmanuel Maille, however, it was the desire to demonstrate that he could apply skills gained while working at Roquette, a producer of carbohydrates for several industry sectors, that was a key factor in his decision to create a proteomics-based company - Proteaxis - providing services to life-sciences companies. As CEO, together with a colleague with proteomics expertise who took on the role of Scientific Director, he built the company to the point where it was performing contract research for several major biopharma and agri-food companies and had grown to 11 employees.

However, after 5 years of operating, the increasingly challenging environment for service-based companies, and the consequent non-renewal of key contracts, led Maille to make the difficult decision to close the company. "We had strong expertise, which is why we survived for 5 years, but a real lack of uniqueness and proprietary technologies that made us weak in a very competitive market," recalls Maille. "If I was to give some advice now to other people considering starting their own service-oriented company, it would be that I believe it is crucial to avoid having too much dependence on a small number of clients, especially in the field of biotechnology, where the clients are mainly large pharma companies. They have very long decision-making processes and are often liable to strategy evolution that you can't control or plan. The impact on the viability of your company can be dramatic, as I found."

So, what next? "After closing Proteaxis, I couldn't imagine moving to a position without challenges," says Maille. "However, time was also an important factor in my choice. The situation for entrepreneurs in France is not good if their company is closing, as this is considered much more as a failure than in the US, where greater emphasis is given to the value of experience and lessons learned," Maille says. "So, I needed to rapidly mobilize my networks to find an appropriate and exciting position."

This led to Maille taking on the role of creating and developing a new business unit providing protein engineering and production services for Proteus, an established French biotech company. "The position offered by Proteus was really attractive because of the strategic challenge - developing a new business model - where I could use the skills I gained at Proteaxis," he says. Maille feels that it would have taken much longer to reach such a position without the experience he gained at his own company. "In France, we often consider the risk and the fear of the risk before thinking about the possibility of success in making your dream a reality. Sometimes you win, sometimes you lose, but you always progress. Regarding the closing of my company, I lost... but personally and professionally, I considerably progressed." 